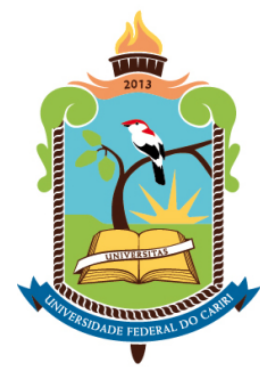

UNIVERSIDADE FEDERAL DO CARIRI

INTITUTO DE FORMAÇÃO DE EDUCADORES

CURSO DE LICENCIATURA INTERDISCIPLINAR EM CIÊNCIAS NATURAIS

E MATEMÁTICA

EDICARLOS PEREIRA DOS SANTOS

OVITRAMPAS: ALTERNATIVA SUSTENTÁVEL PARA O MONITORAMENTO DO Aedes aegypti E FERRAMENTA PARA DIVULGAÇÃO CIENTÍFICA 
EDICARLOS PEREIRA DOS SANTOS

\section{OVITRAMPAS: ALTERNATIVA SUSTENTÁVEL PARA O MONITORAMENTO DO Aedes aegypti E FERRAMENTA PARA DIVULGAÇÃO CIENTÍFICA}

Monografia apresentada ao Curso de Licenciatura Interdisciplinar em Ciências Naturais e Matemática da Universidade Federal do Cariri, como requisito parcial à obtenção do título de graduado em Licenciatura Interdisciplinar em Ciências Naturais e Matemática. Área de concentração: Ciências Biológicas.

Orientadora: Prof ${ }^{\mathrm{a}}$. Dra. Laura Hévila Inocêncio Leite.

Coorientador: Dr. Willian Fernando Domingues Vilela 
Página reservada para ficha catalográfica que deve ser confeccionada após apresentação e alterações sugeridas pela banca examinadora. Para solicitar a ficha catalográfica de seu trabalho, acesse o site: www.biblioteca.ufc.br, clique no banner Catalogação na Publicação (Solicitação de ficha catalográfica) 


\section{OVITRAMPAS: ALTERNATIVA SUSTENTÁVEL PARA O MONITORAMENTO DO Aedes aegypti E FERRAMENTA PARA DIVULGAÇÃO CIENTÍFICA}

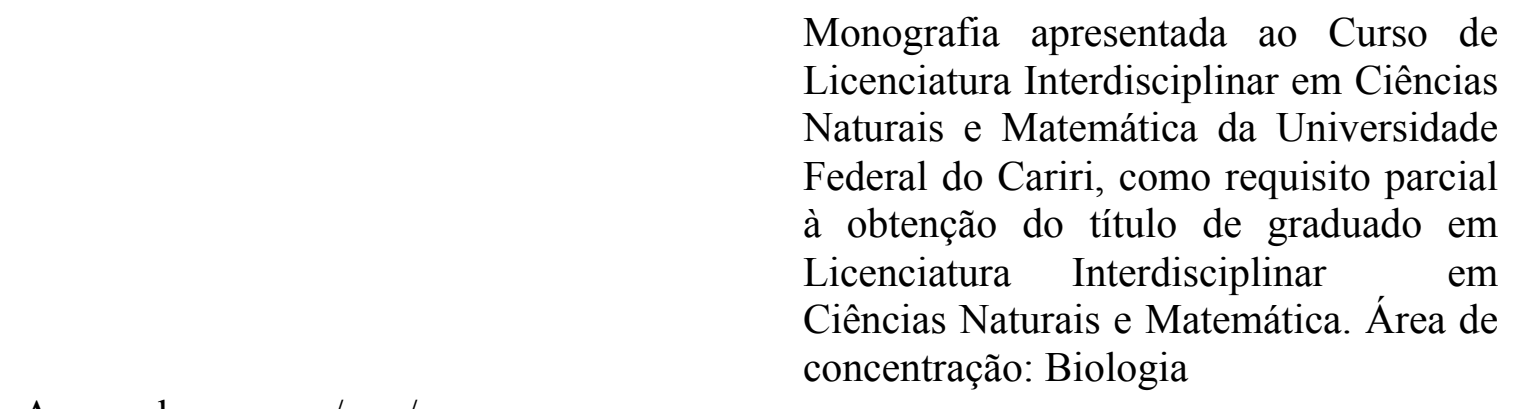

BANCA EXAMINADORA

Prof $^{\mathrm{a}}$. Dra. Laura Hévila Inocêncio Leite (Orientadora) Universidade Federal do Cariri (UFCA)

Prof. Dr. Willian Fernando Domingues Vilela (Co-orientador) Universidade Federal do Cariri (UFCA)

Me. Thales Silva Coutinho (Membro externo) Universidade Federal Rural de Pernambuco (UFRPE)

Dra. Gerlânia de Oliveira Leite (Membro externo) Universidade de Fortaleza (UNIFOR) 
Bem-aventurados os pacificadores, porque eles serão chamados filhos de Deus Mt 05;09 
Dedico a todos os meus familiares, principalmente aos meus pais e minha esposa, e a todos aqueles que me ajudaram, por colaboração e motivação. 


\section{AGRADECIMENTOS}

Agradeço primeiramente a Deus por ter me dado coragem para enfrentar essa longa batalha, pela fé, por ter iluminado minha mente e me dado entendimento e sabedoria para resolver atribuições que me são confiadas, dou graças também pela proteção e companheirismo em todas as horas da minha vida, e também por me conceder trabalho, saúde, e disposição para trabalhar. Agradeço também aos meus familiares, colegas, professores, amigos, a minha orientadora, co-orientador, enfim, a todos que me ajudaram.

Que Deus abençoe 


\section{RESUMO}

O Aedes aegypti é o responsável pela transmissão de várias arboviroses como a dengue, pela falta de controle que muitas vezes está ligado ao pouco conhecimento sobre o grave problema ecológico. Isso significa que muito ainda tem que ser feito no sentido de garantir a proteção eficaz para a população, contra o Aedes aegypti. A ovitrampa é um recipiente de cor escura com capacidade de $500 \mathrm{ml}$ nesta, adere-se um material áspero que é denominado palheta onde permite a fixação dos ovos depositados. O uso e monitoramento de áreas com o auxílio de ovitrampas é um método conhecido por alguns que trabalham na área de endemias e do ministério da saúde. São úteis para averiguação da presença e distribuição de fêmeas do vetor, detectar pontos críticos de concentração populacional e apresentar alternativa ao monitoramento desses vetores que causam a dengue, e apresenta-se de maneira eficaz e de simples reprodução. Esta pesquisa buscou, apresentar essa alternativa sustentável, ao monitoramento de mosquitos que causam a Dengue, em um minicurso durante a IV semana do meio ambiente. Foi feita a instalação e monitoramento das armadilhas no campus da UFCA em Brejo Santo-CE durante a IV semana do meio ambiente, a qual aconteceu no período de 20 a 23 de agosto de 2018, Neste intervalo foi ministrado um minicurso por nome "Fabricação e utilização de Ovitrampas", contou-se com a participação de 18 alunos inscritos, onde além de demonstração prática buscamos identificar se existia infestação nos locais nos quais colocamos armadilhas. Foram instaladas 5 ovitrampas de forma sequenciadas, sendo estas, colocadas em locais úmidos, sombreados e a um metro do solo. Em decorrência do monitoramento, alguns dias antes da apresentação do minicurso obteve-se positividade em uma armadilha de ovoposição. A implantação da ovitrampa nesse lugar foi de grande viabilidade, pois serviu de capacitação e divulgação para os participantes do minicurso. Além disso, foi possível verificar por meio de uma das armadilhas apresentarem positividade, que o local apresenta um índice de infestação igual a 20\%, levando em consideração o IPO (índice de positividade de ovirampa), esse dado é de suma importância para os gestores da UFCA se posicionarem a fim de eliminação de focos neste ambiente universitários. Ainda, os participantes do minicurso, serão disseminadores das informações e formas de monitoramento, dessa forma, há uma possibilidade de alcançar outras áreas que apresentem possíveis riscos. Por fim, esse trabalho é de suma importância, pois por meio dele é possível verificar locais que apresentem população de Aedes aegypti com medida direta de população de adultos e por conseguinte, criar estratégias junto ao poder público e comunidade acadêmica, a fim de reduzir os índices, utilizando alternativas de baixo custo e com materiais sustentáveis.

\section{Palavras chaves: Dengue. Monitoramento. Ovitrampas. Palhetas}




\begin{abstract}
Aedes aegypti is responsible for the transmission of several arboviruses such as dengue due to the lack of control that is often linked to the lack of knowledge about the serious ecological problem. This means that much still has to be done in order to ensure effective protection for the population against Aedes aegypti. The ovitrampa is a container of dark color with capacity of $500 \mathrm{ml}$ in this, it adheres itself a rough material that is denominated vane where it allows the fixation of the deposited eggs. The use and monitoring of areas with the help of ovitraps is a method known to some in the area of endemics and the ministry of health. They are useful for ascertaining the presence and distribution of females of the vector, to detect critical points of population concentration and to present an alternative to the monitoring of these vectors that cause dengue, and presents itself in an effective and simple reproduction way. This research aimed to present this sustainable alternative to the monitoring of mosquitoes that cause Dengue in a mini course during the fourth environmental week. Traps were installed and monitored at the UFCA campus in Brejo Santo-CE during the fourth environmental week, which took place from August 20 to 23, 2018. During this period, a mini-course was given by the name "Manufacture and use of Ovitrampas ", we counted on the participation of 18 enrolled students, where besides practical demonstration we tried to identify if there was infestation in the places in which we put traps. Five sequenced ovitraps were placed in a humid, shaded and one meter of soil. As a result of the monitoring, a few days before the presentation of the mini-course, a positivity trap was obtained. The implantation of ovitrampa in this place was very viable, since it served as training and dissemination for the participants of the mini-course. In addition, it was possible to verify by means of one of the traps positive, that the site presents an infestation index equal to $20 \%$, taking into account the IPO (ovirampa positivity index), this data is of paramount importance to the managers of UFCA to position themselves in order to eliminate foci in this university environment. Also, the participants of the mini-course will be disseminators of the information and forms of monitoring, in this way, there is a possibility of reaching other areas that present possible risks. Finally, this work is extremely important because it is possible to verify sites with a population of Aedes aegypti with direct measurement of the adult population and, therefore, to create strategies with the public power and academic community, in order to reduce using lowcost alternatives and sustainable materials
\end{abstract}

Keywords: Dengue. Monitoring. Ovitrampas. Reeds 


\section{LISTA DE FIGURAS}

Página

FIGURA 01: CICLO DE VIDA DO AEDES AEGYPTI 19

FIGURA 02: PREPARAÇÃO DE OVITRAMPAS $\mathbf{2 6}$

FIGURA 03: INSTALAÇÃO DE OVITRAMPAS $\mathbf{2 6}$

FIGURA 04: DEMONSTRAÇÃO DO BALDE COM PALHETA 27 


\section{LISTA DE GRÁFICOS}

Página

Gráfico 01: INDICE DE INFESTAÇÃO PREDIAL EM BREJO SANTO ANO $2016 \quad 2$

Gráfico 02: INDICE DE INFESTAÇÃO PREDIAL EM BREJO SANTO ANO 2017 2'

Gráfico 03: INDICE DE INFESTAÇÃO PREDIAL EM BREJO SANTO ANO 2018 2: 
TABELA

Página

TABELA: PLANILHA DE INSTALAÇÃO E MONITORAMENTO DE ARMADILHAS OVITRAMPAS 


\section{LISTA DE SÍMBOLOS E ABREVIATURAS}

CE

Estado do Ceará

Ed.

Editora/edição

Ae. Aegypti

Aedes aegypti

Ae.Albopictus

Aedes albopictus

${ }^{\circ} \mathrm{C}$

Graus Celsius

DENV

Vírus da dengue

FIOCRUZ

Fundação Oswaldo Cruz

FUNASA

Fundação Nacional de Saúde

IB

Índice de Breteau

IDO

Índice de Densidade de Ovos

IPO

Índice de positividade de ovitrampa

IP

Índice de positividade

OVT

Ovitrampa

ACE

Agente de combate às Endemias 


\section{SUMÁRIO}

1 INTRODUÇÃO

2 OBJETIVOS

17

2.1 Objetivo Geral

17

2.2 Objetivos específicos

3 REFERENCIAL TEÓRICO

18

3.1 Aedes Aegypti (família, ciclo e mosquito (imagens) 18

3.2 Dengue (tipos, ocorrência - dados locais)

3.3 importância dos ace no combate aos ííndices de infestação 23

3.4 ovitrampas (ferramentas alternativas para medida de positividade do Aedes Aegypti.)

4 METODOLOGIA

4.1 Delimitação de área de estudo

4.2 Aplicação de minicurso

5 RESULTADOS E DISCUSSÃO

6 CONCLUSÃO

7 REFERÊNCIAS

8 ANEXOS 


\section{INTRODUÇÃO}

Entre os vetores de diversas doenças endêmicas existentes no mundo, o Aedes aegypti se mostra como o principal vilão. Esse mosquito é o causador da dengue a qual influencia o maior problema de saúde pública mundial e devido essa grande gravidade é a arbovirose mais importante (TAUIL, 2002).

A primeira epidemia de dengue no Brasil ocorreu em Boa Vista, estado de Roraima em 1981 e 1982, onde 2 sorotipos foram isolados, o 1 e 4, conforme os índices de incidência do País, este estado foi o que apresentou os maiores (REITER; GUBLER, 1988). Podemos confirmar que em todo mundo, essa doença atinge uma base de 5 milhões de casos por ano, 20 mil mortes e também chegando a 500 mil hospitalizações. Com referencia a esses números informados, 95\% dos casos de dengue grave atinge criança com menos de 15 anos (OPAS/OMS, 1999).

Segundo o ministério da saúde o índice de infestação pelo mosquito Aedes aegypti nos anos entre 2009 e 2012 teve um aumento acima de 1\% em grande parte dos estados do Brasil e no estado do Ceará, aonde muitos dos municípios deu o seu índice igual ou acima de $1 \%$, sendo que de acordo com o recomendado pela Fundação Nacional de Saúde não pode ultrapassar 1\%. Essas informações nos mostram uma situação de risco pela qual o nosso país, o estado do Ceará e até mesmo os nossos municípios estão passando. Nós como cidadãos conscientes e também funcionário da saúde tivemos a ideia de usar o trabalho do dia a dia para transformar em algo mais eficaz de grande importância (SIEBRA, 2011)

$\mathrm{O}$ mosquito tem grandes facilidades de se proliferar em áreas urbanas do município, pois ele prefere lugares com aglomerações de pessoas. O combate ao vetor vem apresentando suas dificuldades, e com tudo isso para a eliminação do mosquito podemos detectar ainda alguns pontos críticos, pois o mosquito procura lugares com água limpa para a proliferação (DIVE, 2014).

Existem pontos estratégicos que são lugares preferenciais pelo mosquito, os postos de gasolina e cemitérios, pois são lugares bastante frequentados pelas pessoas e no caso do cemitério, por exemplo, sendo um lugar publico, muita das vezes não tem uma pessoa certa para ficar olhando os vasos periodicamente. Já no caso dos postos de gasolina tem movimento de pessoas e veículos diariamente e o mosquito pode ocorrer situação dele vir embaixo da lona de uma carreta e na parada para abastecimento do veiculo o mosquito sair e fazer morada neste local e causando uma epidemia até mesmo em um bairro ou em uma cidade. 
O combate ao mosquito é feito diariamente pelos profissionais da saúde, diretamente pelo trabalho de grandes esforços dos agentes de combate às endemias (ACE). Esse trabalho é o que chamamos de trabalho focal, o qual foi denominado pelos profissionais da saúde por levantamento de índice mais tratamento ( $\mathrm{LI}+\mathrm{T}$ ). Esse sistema de trabalho é dividido por ciclos anuais, onde o exigido pelo ministério da saúde são 6 ciclos. Ao término de cada ciclo é feito índices, o (IIP) que é o índice de infestação predial, a quantidade de prédios onde são encontradas larvas multiplicados por 100 e dividido pelo total de prédios vistoriados; e o índice de Breteau (IB) que é a quantidade de depósitos onde são encontradas larvas multiplicado por 100 e dividido pela quantidade de imóveis vistoriados pelos agente de endemias (GOMES, 1998).

\section{IIP - $\mathrm{N}^{\mathrm{o}}$ de imóveis positivos para Aedes aegypti X 100 \\ $\mathrm{N}^{\mathrm{o}}$ de imóveis inspecionados \\ IB - $\mathrm{N}^{\mathrm{o}}$ de depósitos positivos para Aedes aegypti X 100 \\ $\mathrm{N}^{\mathrm{o}}$ de imóveis inspecionados}

Diante de todos os esforços que foram feitos até os dias atuais para o controle da dengue, por exemplo, a falta de indicadores sensíveis da densidade populacional - aliada a carência de investigações que determine o início de densidade vetorial para evitar a circulação de um vírus - significa que ainda muito tem que ser feito para a proteção da população (REITER, et al, 1997; GUBLER, D.J; KUNO, G. et al, 1997; KUNO G., 1995).

A ovitrampa é um recipiente de cor escura com capacidade de $500 \mathrm{ml}$ nesta, adere-se um material áspero que é denominado palheta onde permite a fixação dos ovos depositados, desenvolvida por Fay e Eliason (1966) e depois aprimorada por Reiter e Gubler (1997), foi apontada como uma ferramenta de possibilidades de aplicação e monitoramento de densidade de população do vetor. A avaliação da armadilha prova que ela não é só capaz de fazer a detecção da presença do mosquito, mais também tem possibilidades de gerar estimativas da densidade de fêmeas presentes na localidade, a partir da contagem de ovos coletados no local (ACIOLY, 2006).

Nesse sentido, as ovitrampas, são uma alternativa eficaz para o monitoramento e verificação de áreas mais infestadas e que necessitam de maior uso de técnicas de análise espacial, capazes de detectar pontos e momentos críticos de concentração populacional, poderá transformar o monitoramento por ovitrampas georeferenciadas em um instrumento de grande utilidade para a vigilância vetorial, como indicador de prioridades para ações de controle, permitindo maior agilidade e precisão na tomada de decisões. Além disso, são 
técnicas fáceis de reproduzir, e capazes de integrarem cursos de formação ou eventos científicos a fim de transmitir esse conhecimento para aqueles que tenham interesse, e para um maior número de pessoas possíveis. 


\section{OBJETIVOS}

\subsection{Objetivo Geral}

- Descrever o processo utilizado no monitoramento de um método eficaz para controle do Aedes aegypti em um minicurso na IV Semana de Meio Ambiente do Instituto de Formação de Educadores campus da Universidade Federal do Cariri em Brejo Santo.

\subsection{Objetivos específicos}

- Mostrar o processo utilizado para confecção da Ovitrampa.

- Identificar os melhores pontos para instalação e manutenção da armadilha.

- Apresentar os resultados do Minicurso realizado na IV semana de meio ambiente.

- Demonstrar a eficácia do método através da infestação de vetores da Dengue. 


\section{REFERENCIAL TEÓRICO}

\subsection{Aedes aegypti}

Aedes aegypti é o mosquito transmissor da dengue e da febre amarela urbana. Menor do que os mosquitos comuns, é preto com listras brancas no tronco, na cabeça e nas pernas. Suas asas são translúcidas e o ruído que produzem é praticamente inaudível ao ser humano.

O macho, como de qualquer espécie Aedes aegypti alimenta-se exclusivamente de frutas. A fêmea, no entanto, necessita de sangue para o amadurecimento dos ovos que são depositados separadamente nas paredes internas dos objetos, próximos a superfícies de água limpa, local que lhes oferece melhores condições de sobrevivência. No momento da postura, ou seja, da desova, são brancos, mas logo se tornam negros e brilhantes.

Quando os ovos são colocados no recipiente tem uma coloração clara, ficando-se mais escuros até ficar negro-brilhantes. Na hora da postura acontece a fecundação e o embrião se forma em 48 horas, não existindo água o ovo do mosquito pode permanecer viável por até 492 dias (SILVA, H.H.G.; SILVA,I.G., 1999;SANTOS,2008).

Em média, cada mosquito vive em torno de 30 dias e a fêmea chega a colocar entre 150 e 200 ovos. Se forem postos por uma fêmea contaminada pelo vírus da dengue, ao completarem seu ciclo evolutivo, transmitirão a doença.

O tempo aquático é a partir do ovo ter contato com a água, a duração depende muito da temperatura e alimentação disponível, as larvas se alimentam de matéria orgânica disponível no depósito, o período larvária varia de 5 a 7 dias para se transformar em pupa que dura de 2 a 3 dias para atingir a forma de mosquito em condições propícias (REY, 2011).

Quando chega essa fase adulta, ele apresenta uma coloração escura, escamas cor branca na parte posterior da cabeça e nos segmentos abdominais, e um padrão em forma de lira sobre o dorso (NEVES, 2002). 


\section{FIGURA 01: CICLO DE VIDA DO AEDES AEGYPTI}

\section{Aedes Mosquito Life Cycle}

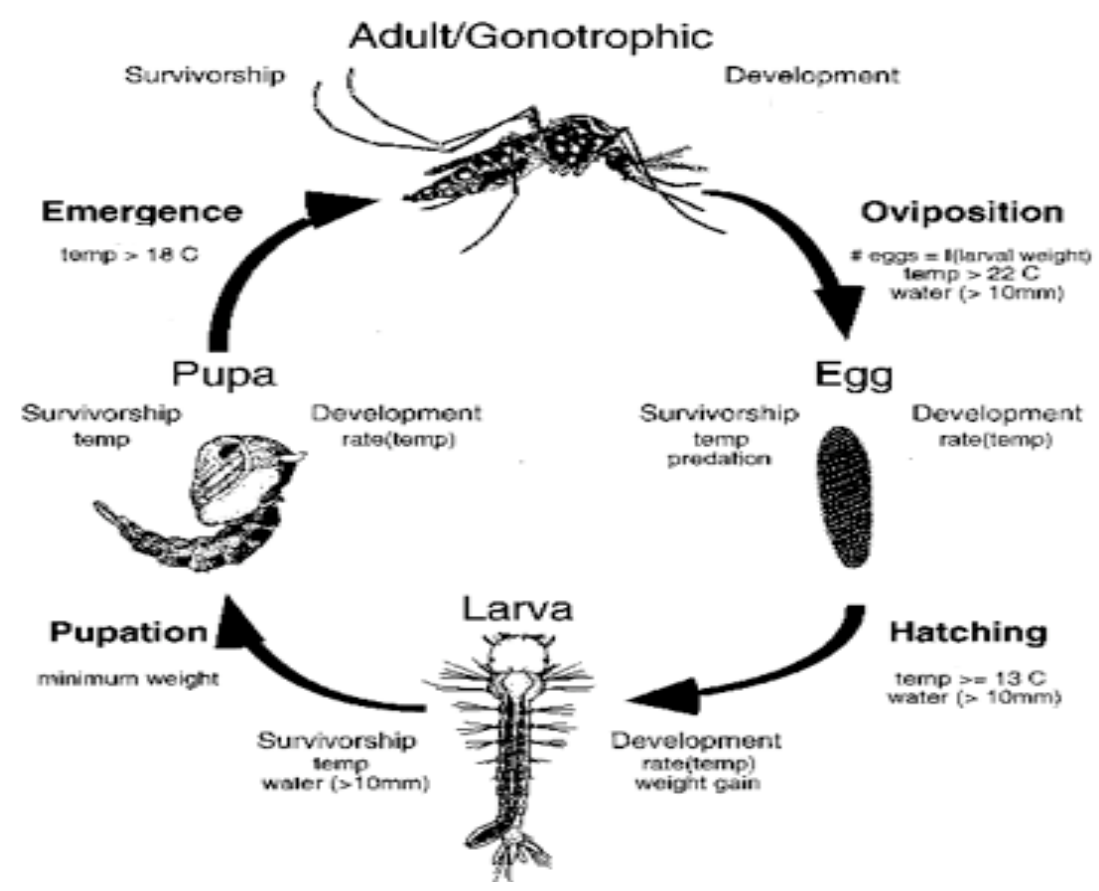

Ciclo de vida do Aedes Aegypti: Demonstração da fase do ovo ate mosquito adulto

Fonte: Hopp MJ and Foley J. Global-scale Relationships betweenClimate and the Dengue Fever Vector Aedes aegypti. Climate Change. 2001; 48: 441-463

O Aedes aegypti, na transmissão do vírus para as pessoas tem preferencia por ambientes internos dos imóveis. Também é comum ser encontrado em áreas urbanas das cidades, geralmente em lugares mais povoados, a reprodução pode ser em depósitos domésticos e onde tiver água parada e limpa (SIVANATHAN, 2006).

O controle do vetor é feito devido o trabalho dos agentes de endemias, aplicação de larvicidas, no trabalho diário para o controle de larvas e aplicação de inseticida para eliminação do mosquito adulto.

O trabalho dos ACE (agentes de combate as endemias) além da vistoria feita nos imóveis tem o preenchimento dos boletins para entregar ao supervisor para prestação de contas do serviço diário. Esses boletins quando são preenchidos usam-se códigos dos depósitos de armazenamento de água, que são denominados.

A1- Depósitos elevados de armazenamento de água elevados para consumo humano: caixas d' água, tambores, depósitos de alvenaria;

A2 - Depósitos ao nível do solo para armazenamento de água para consumo humano: tonel, tambor, barril, tina, depósitos de barro, cisternas, cacimba, poço; 
B - Depósitos móveis: vasos ou frascos com água, prato, garrafas, pingadeiras, recipiente de degelo em geladeiras, bebedouros em geral, pequeno fontes ornamentais, materiais de construção em depósitos como, sanitários estocados, betoneiras, canos e outros, objetos utilizados em rituais religiosos;

C - Depósitos fixos: calhas, lajes e toldos em desníveis, ralos, sanitários em desuso, piscinas não tratadas, fontes ornamentais, floreiras ou vasos em cemitérios, cacos de vidro em muros;

D1 - Depósitos passíveis de remoção ou proteção: pneus e outros materiais rodantes como câmaras de ar, manchões;

D2 - Depósitos passíveis de remoção ou proteção: lixos, como recipientes plásticos, garrafas e latas, sucatas em pátios e ferro velhos e entulhos de construção;

E - Depósitos naturais: axilas de folhas como bromélias, buracos em árvores e em rochas, restos de animais como carapaças.

A ovitrampa ferramenta sustentável, que baseado em estudos pelo programa nacional de controle da dengue incorporou como uma maneira de fácil manuseio e com grandes possibilidades de controle monitoramento do vetor. As ovitrampas captura enormes quantidades de ovos, servindo para realização de estudos e comprovação de áreas de infestação, para direcionar políticas voltadas para áreas de risco (LIMA, 2003).

Essa ferramenta também é utilizada pelo setor de endemia, tanto para controle e monitoramento do Aedes aegypti como para detectar se em alguma localidade existe infestação do mosquito.

As ovitrampas podem ainda, ser tema de divulgação científica, e assim apresentar ao maior número de pessoas possíveis, esta ferramenta ecológica que pode ser tão útil no mapeamento de áreas de infestação de mosquitos transmissores de arboviroses.

\subsection{Dengue}

Dengue é uma doença causada por um vírus, o vírus da dengue, transmitido de uma pessoa doente para uma pessoa sadia por meio de um mosquito, o Aedes aegypti, e ela se desenvolvem de duas formas, no Brasil é comum aparecer de duas maneiras a clássica e a hemorrágica. (BRASIL, 1996, p. 9)

Clássica: Dengue se inicia de maneira súbita com febre alta, dor de cabeça, dor atrás dos olhos, dores nas costas. Às vezes aparecem exantemas (manchas vermelhas no corpo). A febre dura cerca de cinco dias com melhora progressiva dos sintomas em 10 dias. Em alguns 
poucos pacientes podem ocorrer hemorragias discretas na boca, na urina ou no nariz, raramente há complicações

Hemorrágica: Dengue hemorrágica é uma forma grave de dengue, quando se tem a doença uma segunda vez. No início os sintomas são iguais ao dengue clássico, mas após o $5^{\circ}$ dia da doença alguns pacientes começam a apresentar sangramento e choque. Os sangramentos ocorrem em vários órgãos. Alguns doentes apresentam choque circulatório, este tipo de dengue pode levar a pessoa à morte.

Característica epidemiológica e clinica da doença, são do interesse de pesquisa de saúde tanto brasileira como até mesmo internacionais, devido a sua gravidade. É a segunda maior enfermidade transmitida por vetores em termos de número de casos (TEIXEIRA et al., 2009, online).

Um ciclo de trabalho é quando os profissionais de saúde, nesse caso os agentes fazem vistoria em todos esses imóveis, terminando as visitas faz-se o levantamento de tudo que ocorreu durante esse percurso, quantos imóveis foram inspecionados, quantos ficaram pendentes, se aumentou imóvel, se diminuiu quantos deram positivos, etc. todo esse processo deve-se repetir no mínimo 6 vezes por ano.

Nos quadros abaixo, apresenta índices de casos de dengue durante os anos de 2016, 2017 e 2018 em Brejo Santo;

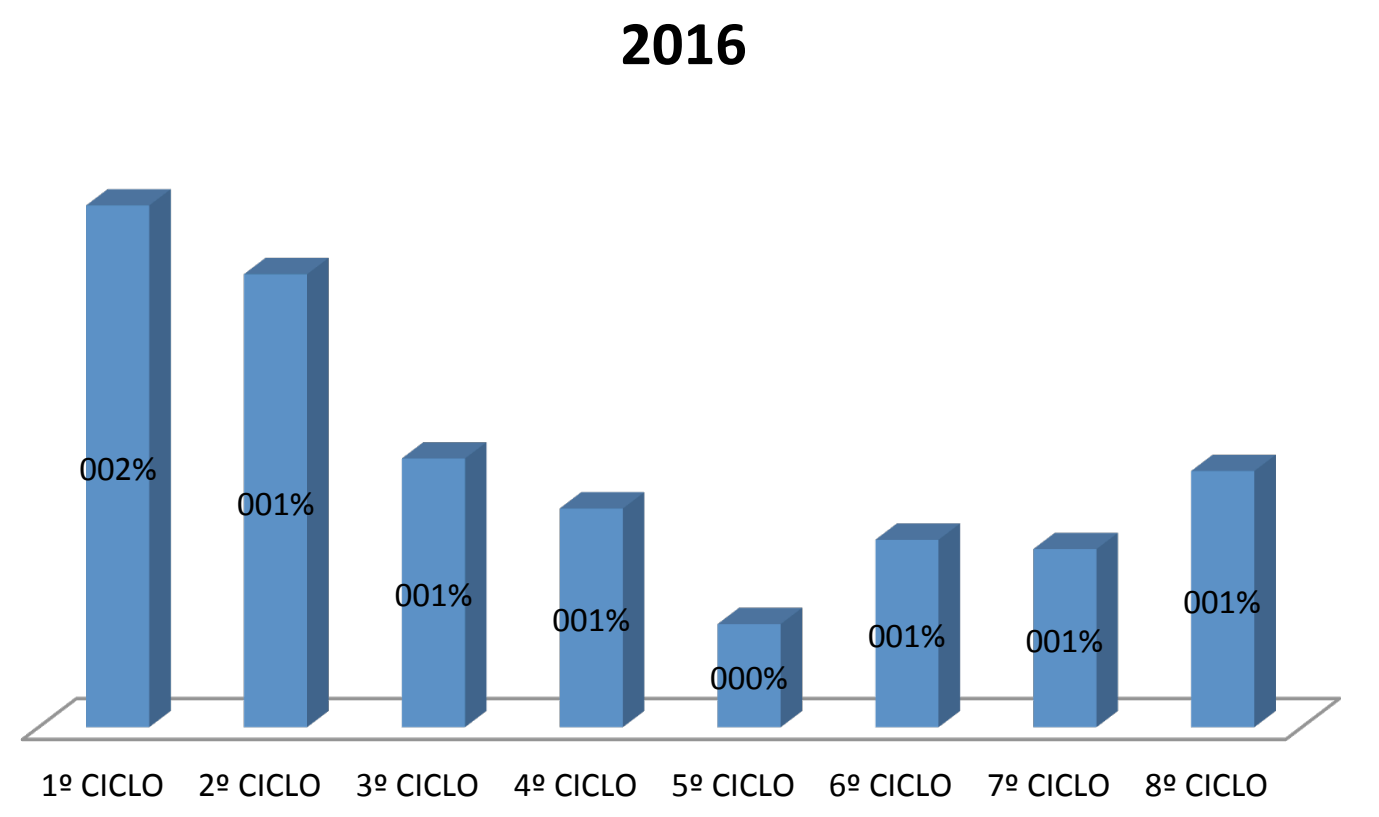

No ano de 2016 foram trabalhados 8 ciclo, onde o $1^{\circ}$ e o $2^{\circ}$ ultrapassou $1 \%$. Considerado epidemia 


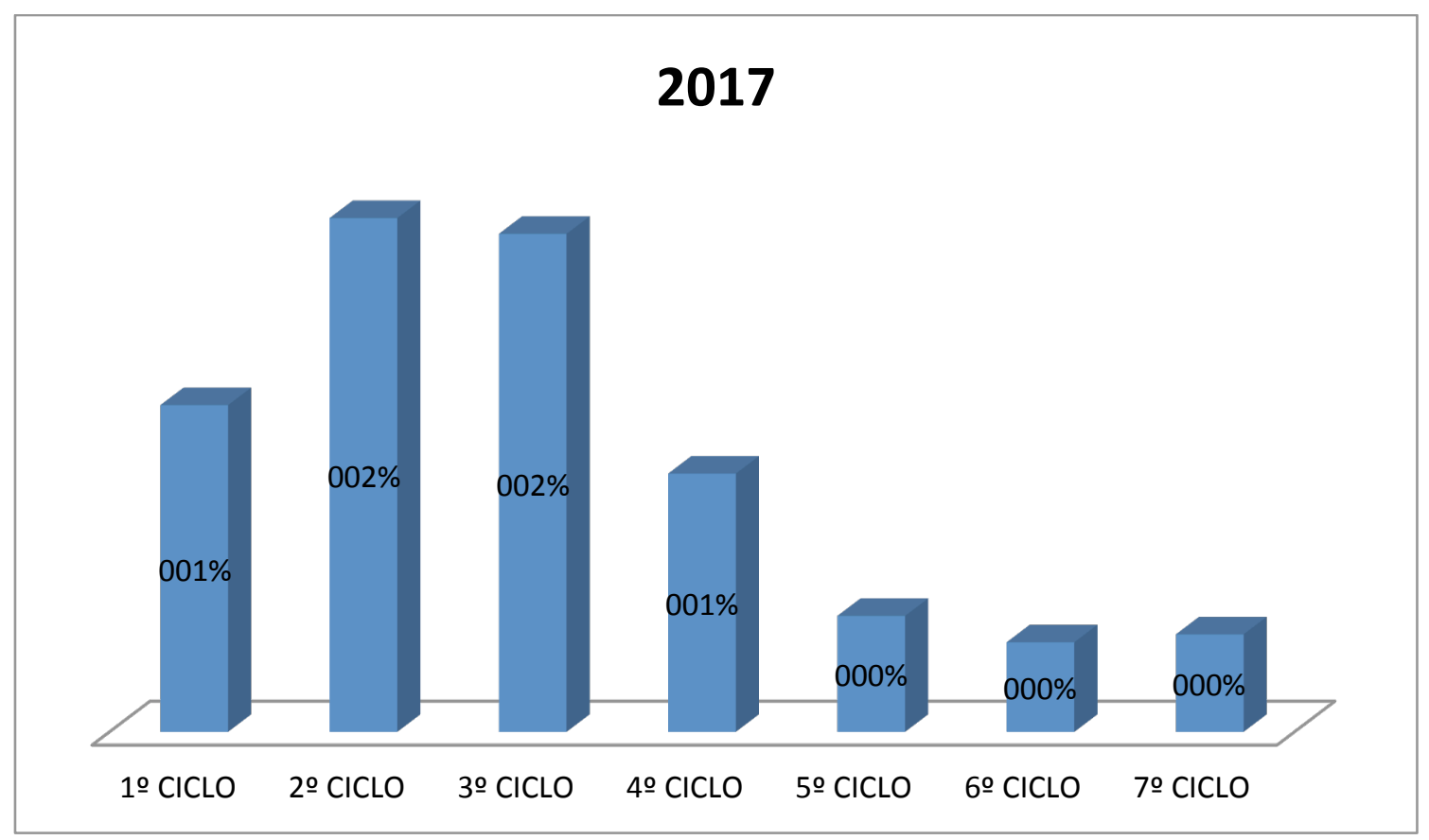

Ano de 2017 considerado epidemia do $1^{\circ}$ ao $3^{\circ}$ ciclo

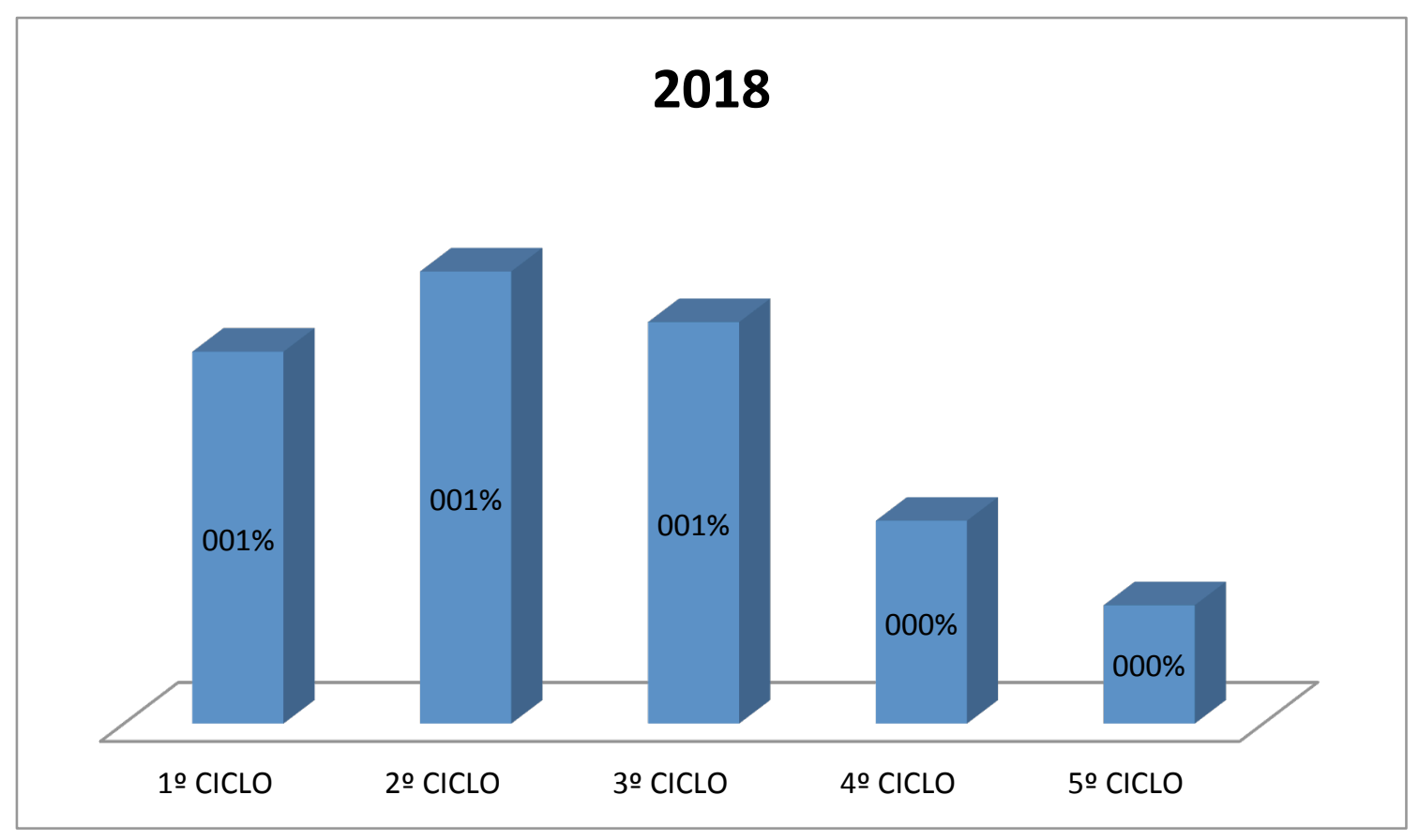

Ano de 2018 só o $2^{\circ}$ ciclo ultrapassou 1\%, considerado epidemia 


\subsection{Importância do Agente de Combate às Endemias (ACE) No Combate aos Índices de infestação}

Conforme o plano nacional de controle da dengue existe três maneiras de controle do mosquito: Químico, biológico e físico (BRASIL, 2009 apud GARCIA, 2016, P. 6).

O uso do controle químico consiste no manejo de compostos químicos que são denominados inseticidas ou pesticidas, que sua função é o combate na fase larvária e também na fase adulta do inseto, os mais utilizados nos trabalhos são dos grupos denominados piretróides e de organofosforados, mais as ações não se limitam só nesses (ERLANGER et al., 2008 apud GARCIA, 2016, P. 6).

Uma das facilidades desse tipo de trabalho é a aceitação do povo, pois a facilidade do uso e a eficácia do combate ao mosquito, apesar da sua resistência. Em certos casos, esse tipo de produto prejudica a saúde da população e dos animais, então são usadas outras situações estratégicas, tipo abordagens biológicas e físicas (BALLENGER-BROWNING; ELDER, 2009; BRAGA; VALLE, 2007 apud GARCIA, 2016, P. 7)

Conforme DONALÍSIO; GLASSER (2002) “Já no controle biológico faz-se o uso de agentes biológico para o controle dos mosquitos adultos ou as larvas".

"O tipo de controle físico são usadas mais ações que não focam em tecnologias como escritas anteriormente, é mais voltadas para esforço ambiental e social. A maior ação utilizada nesse controle são usos de pesticidas, eliminação de criadouros, e prevenção de futuras fontes de procriação, como caixa d'agua, lixos, pneus, etc. O ideal para esse controle é a mobilização da população e conhecimento do povo da localidade a respeito do problema do setor, nesse caso o conhecimento de todos tem papel fundamental" (ERLANGER et al., 2008 apud GARCIA, 2016, P. 7).

$\mathrm{O}$ agente de combate às endemias (ACE) tem função importantíssima diante da população, além da investigação de áreas com índice de infestação, a eliminação de criadouros, de possíveis criadouros, orientação nas comunidades, prevenção de possíveis doenças por meio de orientação e sensibilização ao povo.

\subsection{OVITRAMPAS: FERRAMENTAS ALTERNATIVAS PARA MEDIDA DE POSITIVIDADE DO AEDES AEGYPTI}

Uma alternativa pouco conhecida, a ovitrampa, tanto por usuários de serviços público da saúde como também por até alguns servidores novatos da parte epidemiológica. Essa 
ferramenta é uma alternativa ecossistêmica para o controle do famoso vilão Aedes aegypti, que simula um criadouro perfeito para a desova da fêmea, nela não contém nenhum tipo de inseticida e nem algo que posso prejudicar o meio ambiente e sim, apenas produtos naturais.

As armadilhas de ovoposição conhecidas como ovitrampas, permitem de forma prática e custo baixo uma maneira de determinar se temos presença do Ae. aegypti e Ae. Albopictus por meio de ovos que foram depositados, pois também podemos fazer uma observação de vários tipos de mosquitos e espécies no local (Honório \& Lourenço-de-Oliveira 2001, Braga \& Valle 2007b, Oliveira \& Maleck 2014).

Essa armadilha foi resultado de um estudo no ano de 1965, por Fay e Perry que buscavam elucidar o comportamento de ovoposição de fêmea do Aedes Aegypti. Em vários estudos usaram infusões de diversas matérias orgânicos, como infusões do carvalho branco (PONNUSAMY et al 2008), capim elefante ( SANT'ANA et al, 2006) e a frequentemente a base do feno (MACIEL-DE-FREITAS et al 2008;CHADEE et al 1993), para ter um melhor desempenho da ovitrampa e tornando mais atrativa. Essa atração pode ser determinada pela concentração dos detritos orgânicos ( MURREL \& JULIANO, 2008).

O primeiro registro de uso dessa ferramenta chamada ovitrampa para controle do mosquito Aedes aegypti foi em Cingapura (CHAN et al, 1973). 


\section{METODOLOGIA}

\subsection{Delimitação de área de estudo}

A cidade de Brejo Santo, estado do Ceará faz trabalho de controle ao Aedes Aegypti na sede, incluindo todos os bairros e em algumas localidades da zona rural, onde são deliberados pelo CRES da região, que é a 19a . Conforme dados informados no centro de zoonoses do município são trabalhados uma quantidade de 20.186 imóveis sede e zona rural.

Pois, a realização da pesquisa foi na Escola de Ensino Médio Técnico e Integral José Teles de Carvalho localizada, conhecida como Liceu na cidade de Brejo Santo-CE, onde está funcionando o Campus da UFCA, Universidade Federal do Cariri. Foi escolhido para pesquisa por motivo de grande concentração de pessoas, inclusive os alunos do Liceu e também os alunos da Universidade e também para a questão do monitoramento que fica mais acessível.

\subsection{Aplicação de minicurso}

No Período de 20 a 23 de agosto de 2018, dias que aconteceram a IV semana do meio ambiente do Instituto de Formação de educadores em Brejo Santo, campus UFCA, foi ministrado um minicurso por nome" Fabricação e Utilização de Ovitrampas", contou-se com a participação de 18 alunos inscritos. Esse minicurso foi ministrado da seguinte maneira, no primeiro encontro foi feito aula teórica, explicação sobre instalação, locais adequados, implantação e monitoramento dessa ferramenta, também durante essa aula foram debatidos alguns assuntos relacionados ao vetor, como lugares propícios, ciclo de vida e também durante a apresentação de slides foi mostrado imagens de ovos, larvas e pupas do mosquito. No segundo encontro foi realizado demonstração de palhetas contendo ovos do mosquito Aedes Aegypti e também foi mostrado garrafas pets com exemplo de larvas e pupas, após essa demonstração fomos para aula prática de campo fazer retirada de palhetas das ovitrampas que tinham sido instaladas dias anteriores. Durante a aula de campo nas retiradas de palhetas foi detectada uma das 5 com positividade.

Para o cálculo do índice de positividade (IPO) multiplica o número de armadilhas positivas da área por cem e divide o resultado pela quantidade de armadilhas examinadas (FAY \& ELIASON, 1966 APUD GOMES, 2002). 
A ovitrampa pode ser confeccionada em casa mesmo, ferramenta de baixo custo e eficiente, corta-se uma garrafa pet, pinta de preto e coloca uma palheta de Eucatex presa com um clip ficando com a parte áspera para o interior da armadilha.

Muitos estudos mostram a instalação da ovitrampa com feno e com água no seu interior. Para preparar as infusões em alguns testes foram utilizados três tipos de materiais orgânicos com base em estudos em tempos passados (SANTANA et al, 2006; CHADEE et al 1993; MACIEL-DE-FREITAS et al 2008).

$\mathrm{Na}$ instalação, deve-se deixar de $1 \mathrm{~m}$ ou 1,5 de altura do chão, em lugar que tenha sombra, livre de chuva, onde não animais não tenha contato e fazer troca de palheta 1 vez por semana e não esquecer de colocar água no seu interior.

FIGURA 2: PREPARAÇÃO DE OVITRAMPAS

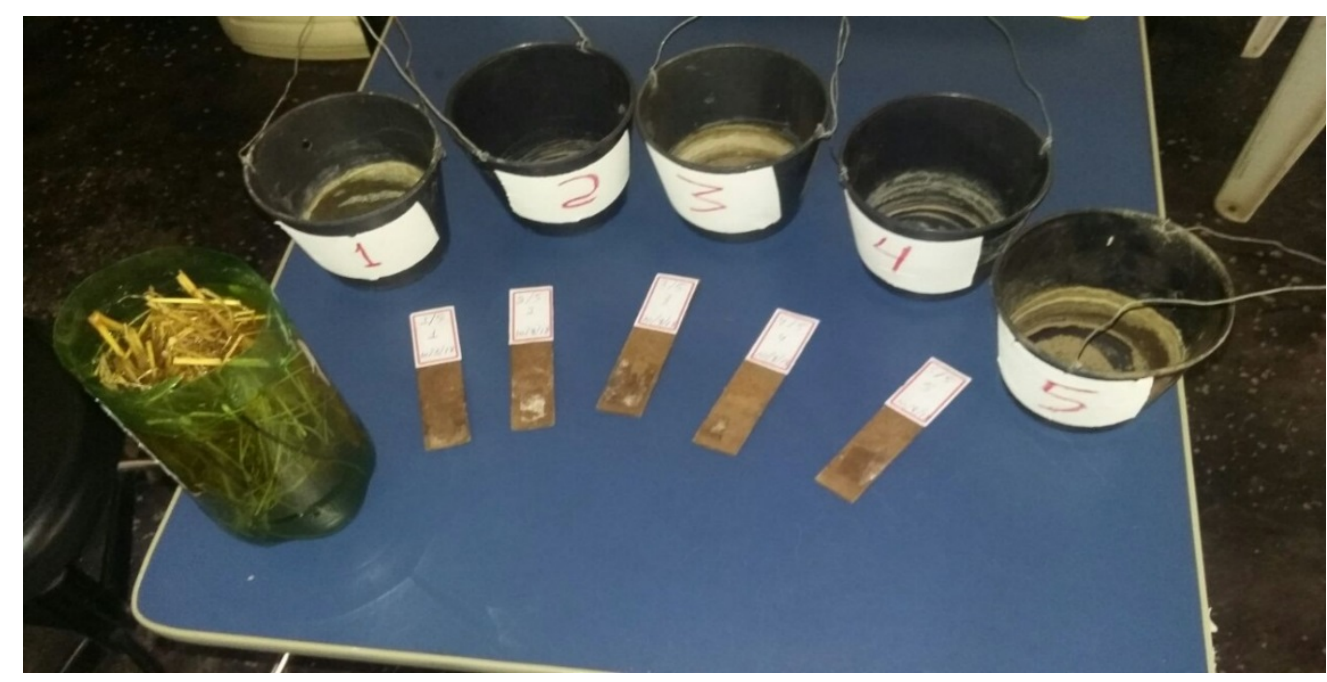

FIGURA 3: INSTALAÇÃO DE OVITRAMPAS

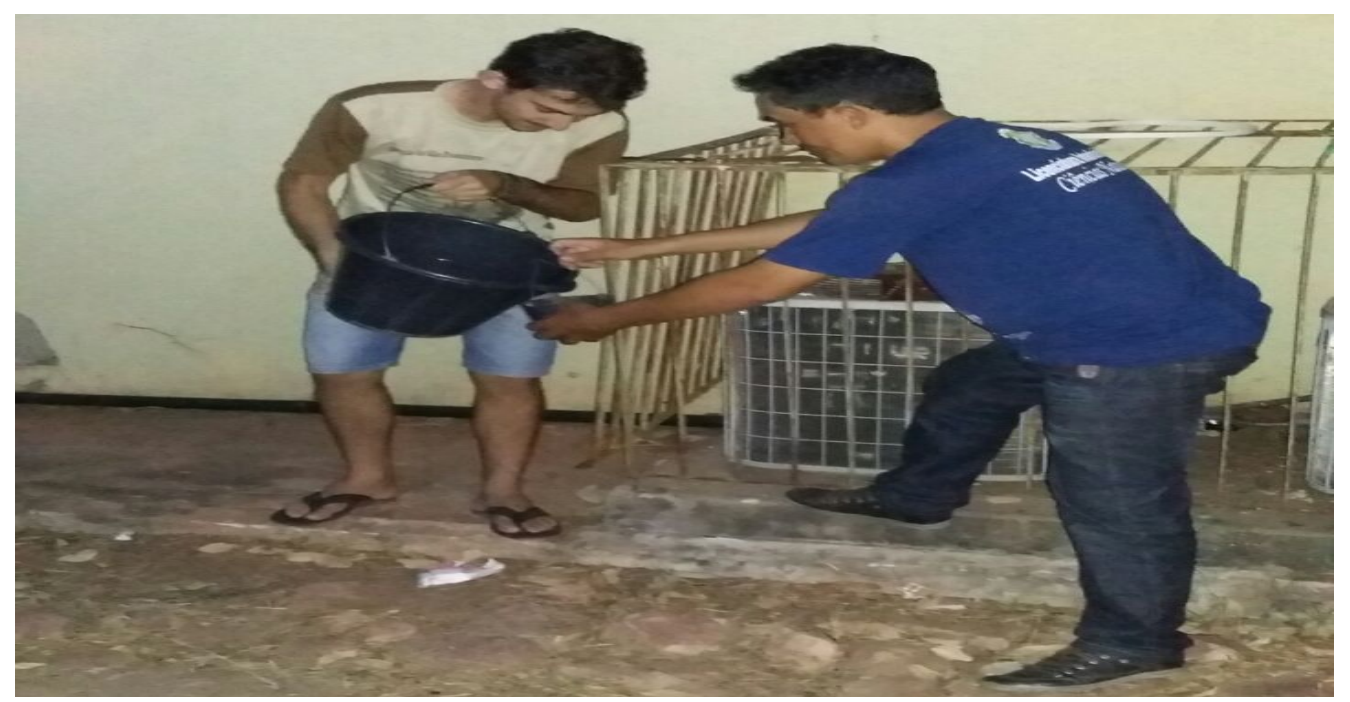


FIGURA 4: DEMONSTRAÇÃO DO BALDE COM PALHETA

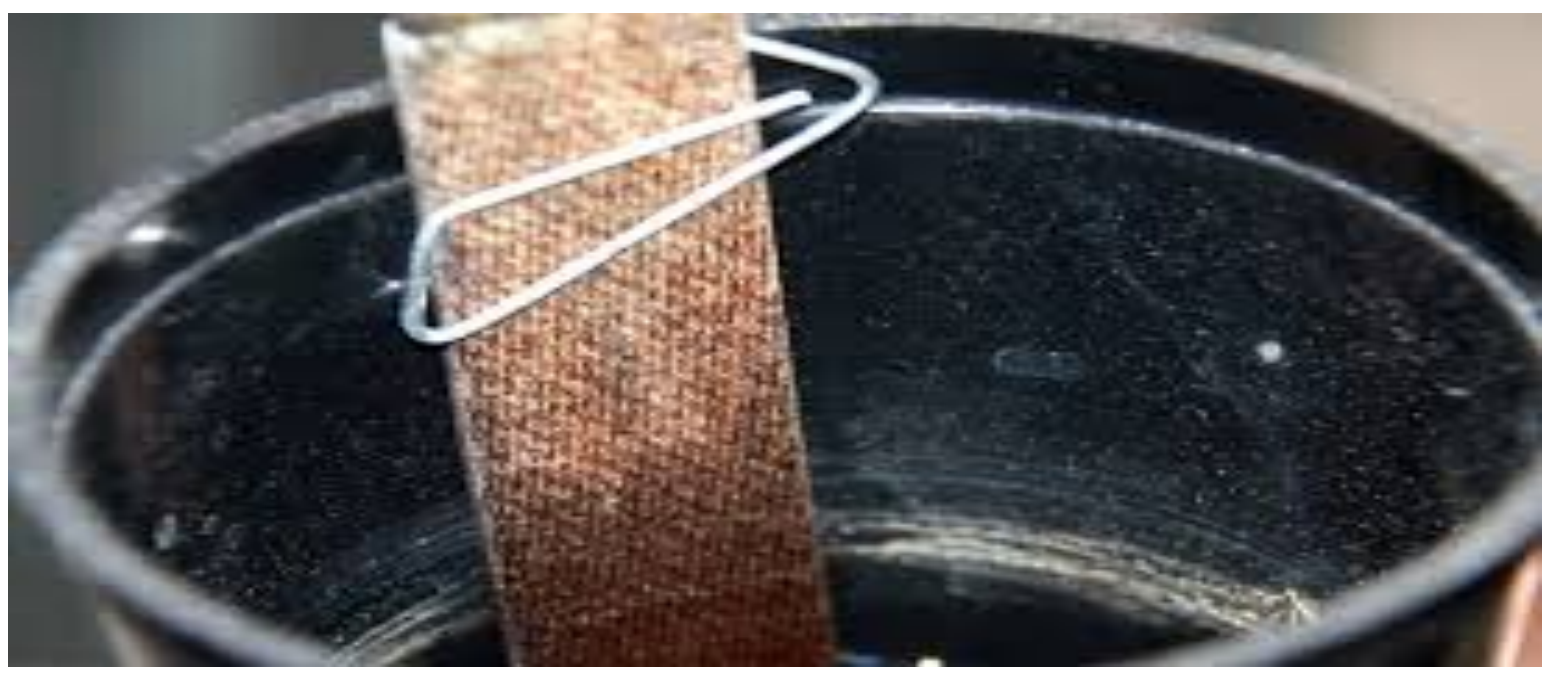




\section{RESULTADOS E DISCUSSÃO}

O trabalho dos agentes de endemias é feito através de ciclos. Exemplo: conforme informação coletada no centro de zoonoses de Brejo Santo pode confirmar que o município hoje possui 20.186 imóveis atualizados onde é realizado trabalho de combate ao Aedes aegypti.

Durante todos ciclos de trabalho focal dos agentes de endemias na cidade de Brejo Santo-CE, do ano 2016 até 2018 todos tiveram índice de infestação (IIP), ou seja imóveis positivos para o mosquito. No ano de 2016 foram realizados 8 ciclos, em 2017 foram feitos 7 e 2018 até agora concluíram o $5^{\circ}$ ciclo, em 2016 somente o $1^{\circ}$ e $2^{\circ}$ ultrapassaram 1\%. $20171^{\circ}$, $2^{\circ}$ e $3^{\circ}$ ultrapassaram $1 \%$ e 2018 somente o $2^{\circ}$ ultrapassou $1 \%$. Esses foram dados informados no setor de endemias de Brejo Santo, conhecido também como centro de Zoonoses do Município, esses foram os ciclos de trabalhos dos agentes de endemias durante esses períodos citados, isso significa que o Município tem índice de infestação. Esses dados que foram apresentados serve para justificar a importância do monitoramento em áreas de risco e de concentração de pessoas, onde o Liceu é uma dessas.

A instalação e monitoramento das armadilhas realizou-se no campus da UFCA em Brejo Santo na escola de Ensino Médio Técnico e Integral José Teles de Carvalho -Liceu antecedendo alguns dias da IV semana do meio ambiente iniciou-se o processo de instalação e manutenção das armadilhas de ovoposição aos redores do prédio.

Finalizando o minicurso analisando se a localidade estudada, lugar onde foi feito a implantação e monitoramento das ferramentas sustentável conhecida como ovitrampas tem índice de infestação, pois como resultado foi detectado que o lugar é positiva, das ovitrampas instaladas uma obteve positividade.

Como prova que a localidade possui resultado positivo para focos do mosquito, uma das cinco armadilhas obteve positividade para o ovo do Aedes aegypti. Constatou-se que o local onde houve a positividade era propício ao vetor devido a aglomeração de pessoas, alta umidade e por estar em uma parte sombreada.

O feno produzido a base de capim colonião, que existe em suas principais qualidades a produção de feno, relaciona caule: folha com a presença de caule fino, pois além de possui um grande valor nutritivo, fica mais fácil o processo de desidratação ( LIMA \& CUNHA, 2008). 
Pois o feno é uma solução feita de capim, onde o capim é cortado, colocado de molho na água e depois de alguns dias coa, coloca em garrafas petes e vai para o campo para abastecimento das ovitrampas.

Como foi relatado que usa-se além do feno produzido desses materiais citados anteriormente, na instalação de ferramentas ovitrampas foram colocadas água da torneira nos baldes até chegar nos furos (RODRIGUES, 2005, p. 14).

No ano de 1991 em um estudo para instalação de ovitrampas foi utilizado a infusão do feno a base de $10 \%$ adicionado água da armadilha, mostrou ser mais eficaz para a ovoposição, gerando uma atração maior para o mosquito aedes aegypti e tendo um aumento de aproximidade 8 vezes a quantia de ovos, comparando as armadilhas que continham só água no seu interior, (REITER ET AL.1991).

PLANILHA DE INSTALAÇÃO E MONITORAMENTO DE ARMADILHAS OVITRAMPAS

\begin{tabular}{|c|c|c|c|}
\hline INSTALAÇÃO & COLETA & $\begin{array}{c}\text { QUANTIDADE DE } \\
\text { OVITRAMPAS }\end{array}$ & $\begin{array}{c}\text { QUANTIDADE DE } \\
\text { OVITRAMPAS POSITIVAS }\end{array}$ \\
\hline $10 / 08 / 2018$ & $13 / 08 / 2018$ & 05 & 00 \\
\hline $13 / 08 / 2018$ & $17 / 08 / 2018$ & 05 & 01 \\
\hline $17 / 08 / 2018$ & $21 / 08 / 2018$ & 05 & 00 \\
\hline
\end{tabular}




\section{CONCLUSÃO}

Conclui-se, que o monitoramento de infestação de fêmeas do Aedes aegypti pode ser um procedimento simples e fácil, feito por meio de ovitrampas. Esse monitoramento permite avaliar áreas mais ou menos infestadas, e comparar os indicadores que levam a aumento do número de positividade. Ainda, que este experimento, foi de grande relevância, oferecendo formação complementar a todos os 18 estudantes inscritos no minicurso, e que participaram ativamente dos dois dias de conteúdos teóricos, e prática investigativa, demonstrando a importância de combate ao vetor da dengue, e métodos diagnósticos para áreas de risco.

Os agentes de endemias (ACE) tem papel fundamental na sociedade, são eles que identificam locais com focos, fazem eliminação de criadouros do mosquito, por meio de larvicida, inseticida, ou seja, ele faz o trabalho de prevenção e eliminação de criadouros tanto do Aedes aegypti como também de outros insetos que causam problemas a saúde pública. 


\section{REFERÊNCIAS}

REITER, P.; GUBLER, D. J. Surveillance and control of urban dengue vectors. In: GUBLER, D. J.; KUNO, G. Dengue and dengue hemorrhagic fever. New York: New York CAB, 1988.

GOMES A. C. Medidas dos níveis de infestação urbana para Aedes (Stegomyia) aegypti e Aedes (Stegomyia) albopictus. Informe Epidemiológico do SUS, Brasília, v. 2, n. 3, p. 4957, jul/set, 1998.

$$
\text { b }
$$

NASCIMENTO, DO.; FELIPE ALBANO MELO. Padronização e implementação do uso de armadilhas de ovoposição nas ações de monitoramento do mosquito Aedes aegypti (Diptera: Culicidae) no município de Natal, RN / Felipe Albano Melo do Nascimento. Natal, 2017.

SILVA, JULIANA CARLA SERAFIM. Avaliação da aplicação de novos métodos de monitoramento populacional na vigilância entomológica em dengue, no município de Ipojuca,

Pernambuco. / Juliana Carla Serafim da Silva. —Recife: J. A. C. da Silva, 2010.

OLIVEIRA, SARA DE SOUZA. Análise espacial e temporal da infestação por Aedes aegyptimensurada por ovitrampas para geração de alerta precoce de dengue no município do Rio de Janeiro. / Sara de Souza Oliveira. --2016.

Nobre,Joana Mary Soares. Participação social e controle da dengue: um processo de implantação da ecosaúde/Joana Mary Soares Nobre. - 2013. CD-ROM 133f. : il. (algumas color.); 4 3/4 pol.

SIEBRA, LUCIANO GUEDES. Sustentabilidade no monitoramento e controle do aedes aegypti: uma alternativa ecossistêmica para uma problemática nacional. 2011

GARCIA, K. K. S. Potenciais estratégias para o controle de populações de Aedes aegypti (Linnaeus, 1762) no Brasil. Monografia de Graduação. Universidade de Brasília. Faculdade de Ceilândia. Brasília, 2016. 58 p.

OLIVEIRA, ALEXANDRE DE ARAUJO. Estudo comparativo sobre a eficácia de dois substratos de oviposição em armadilhas de ovitrampas para vigilância de vetores de dengue no município de Nova Iguaçu, Rio de Janeiro / Alexandre de Araujo Oliveira.- Rio de Janeiro, 2017. xv, 36 f. : il. ; $30 \mathrm{~cm}$. 
estado de santa Catarina e no município de são José do cedro, SC. 2014 OLIVEIRA, CLÁUDIA RENATE TROJAHN. Manografia apresentada ao curso do programa de pós-graduação em educação ambiental, da Universidade Federal de Santa Maria (UFSM, RS) com requisito parcial para obtenção do grau de especialista em educação ambiental. Santa Maria, RS. 2010 


\section{ANEXOS}

FOTOS APRESENTAÇÃO DE MINICURSO: "FABRICAÇÃO E UTILIZAÇÃO DE OVITRAMPAS"

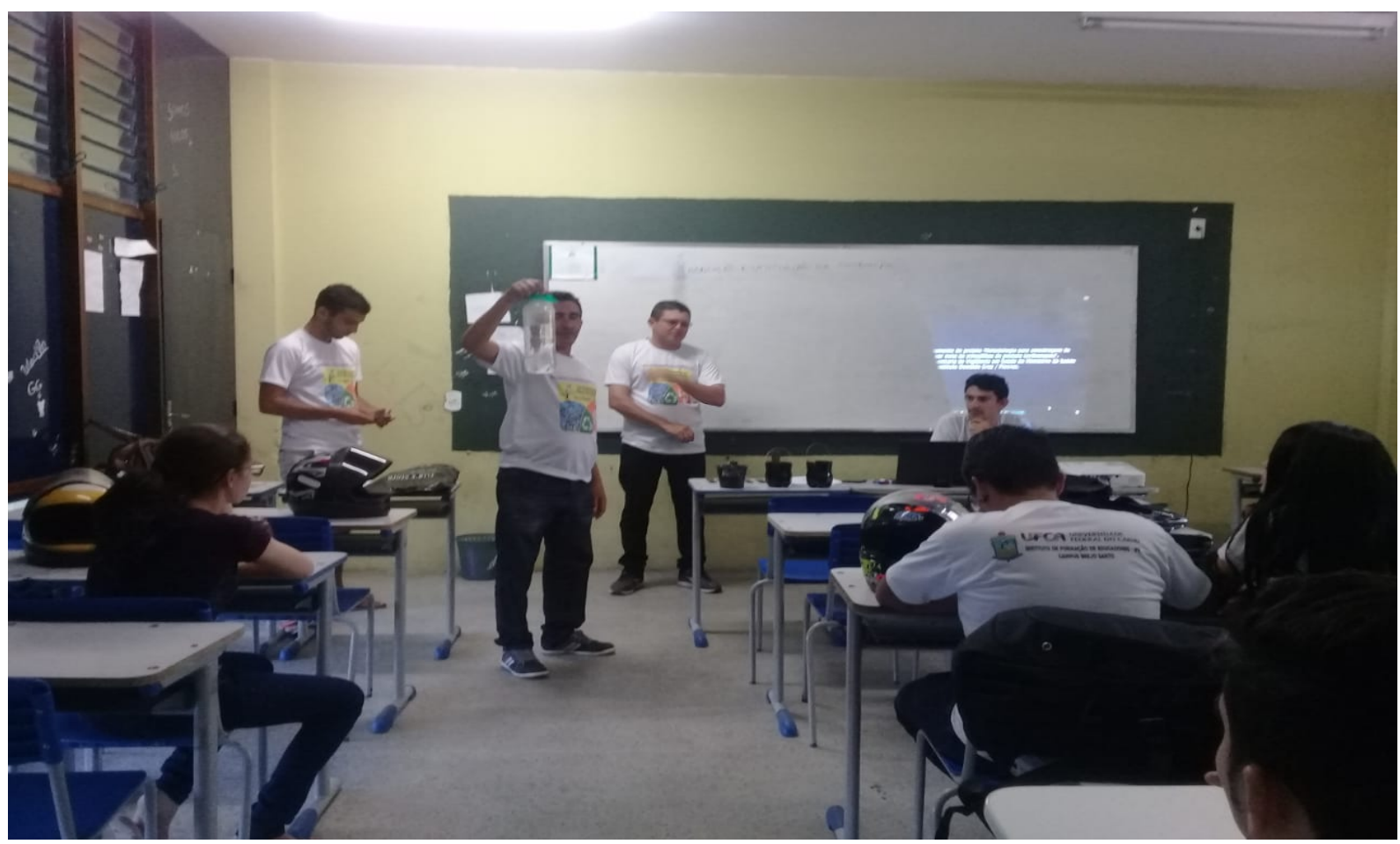



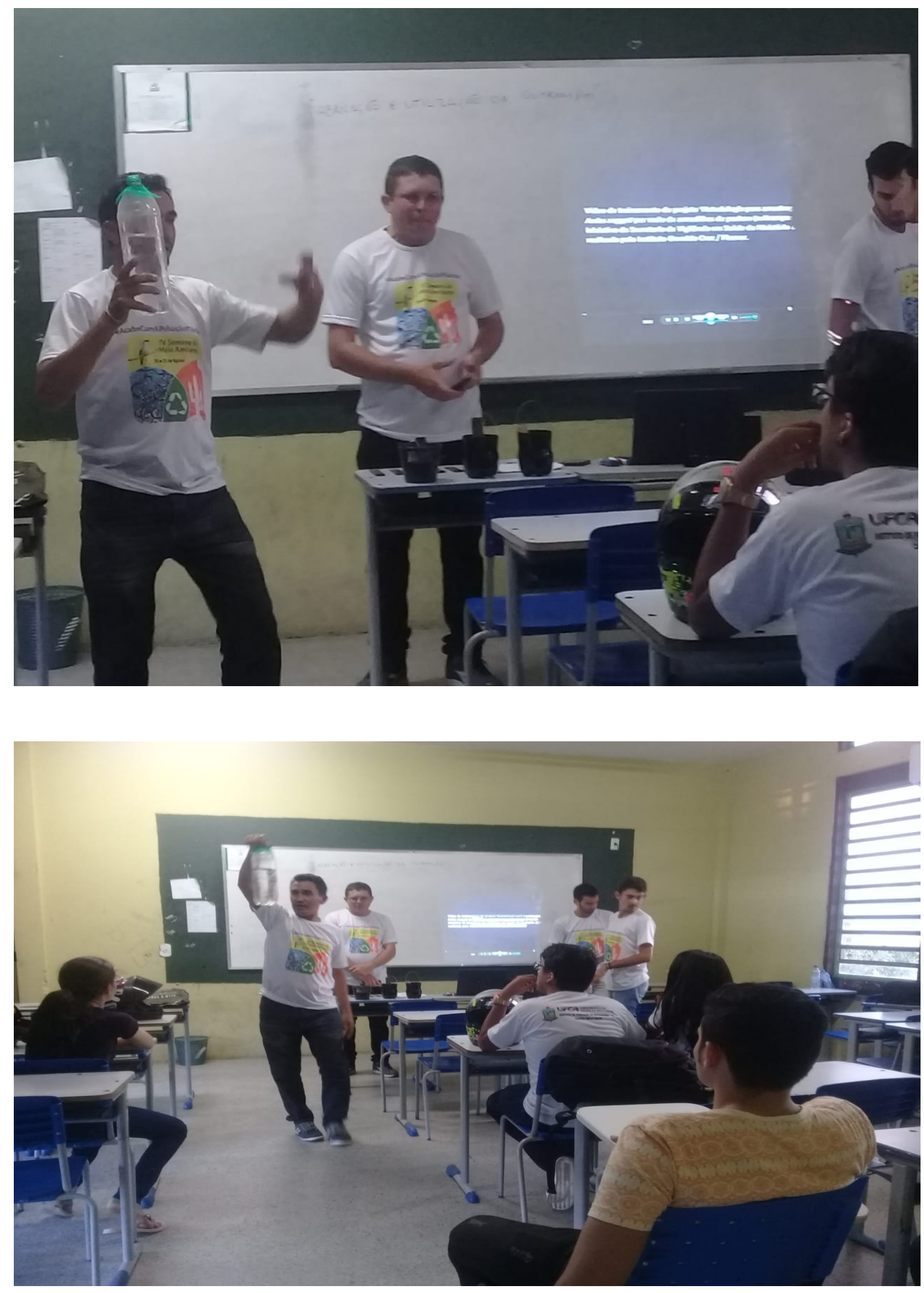


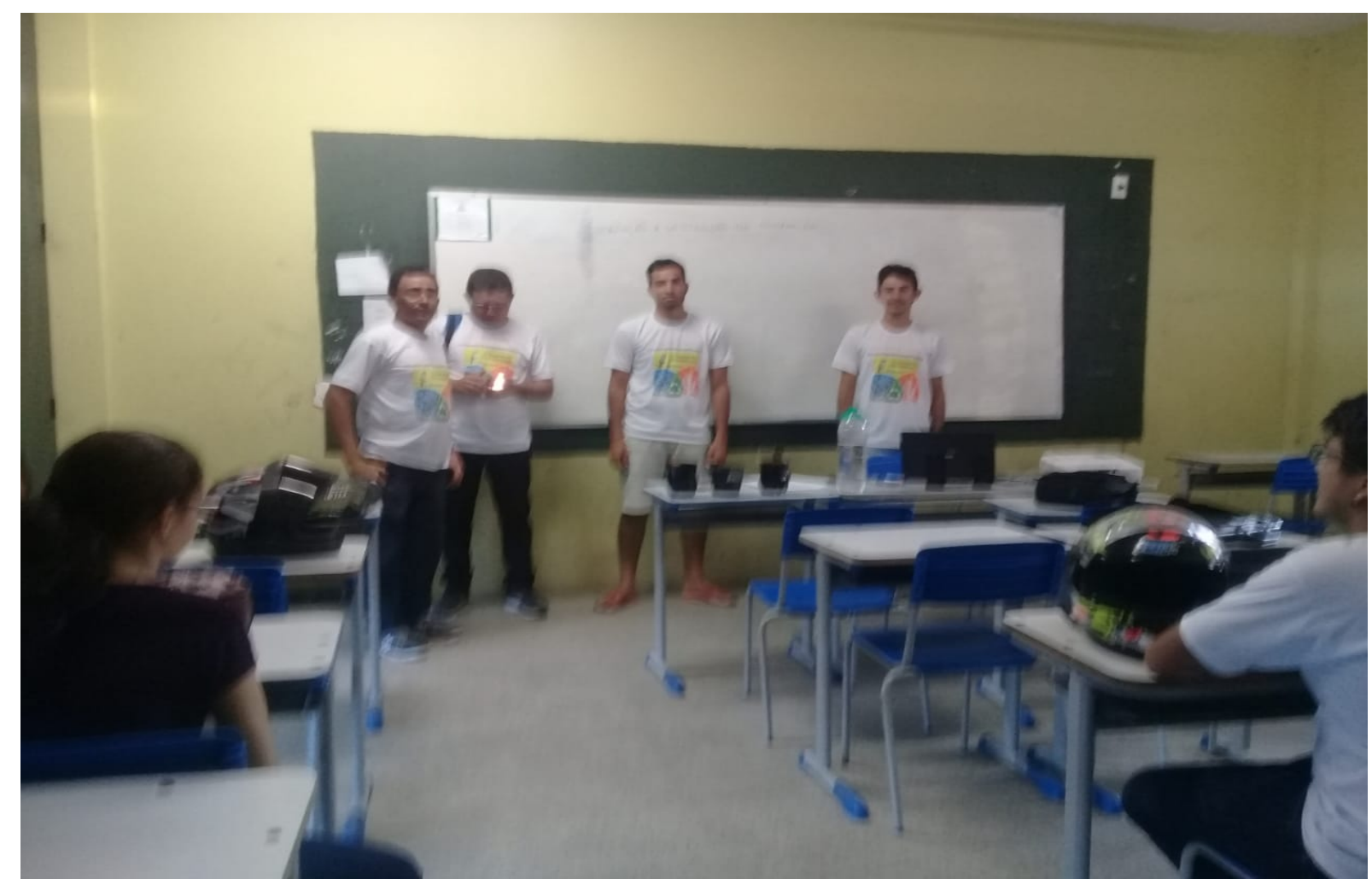

PALHETA NEGATIVA

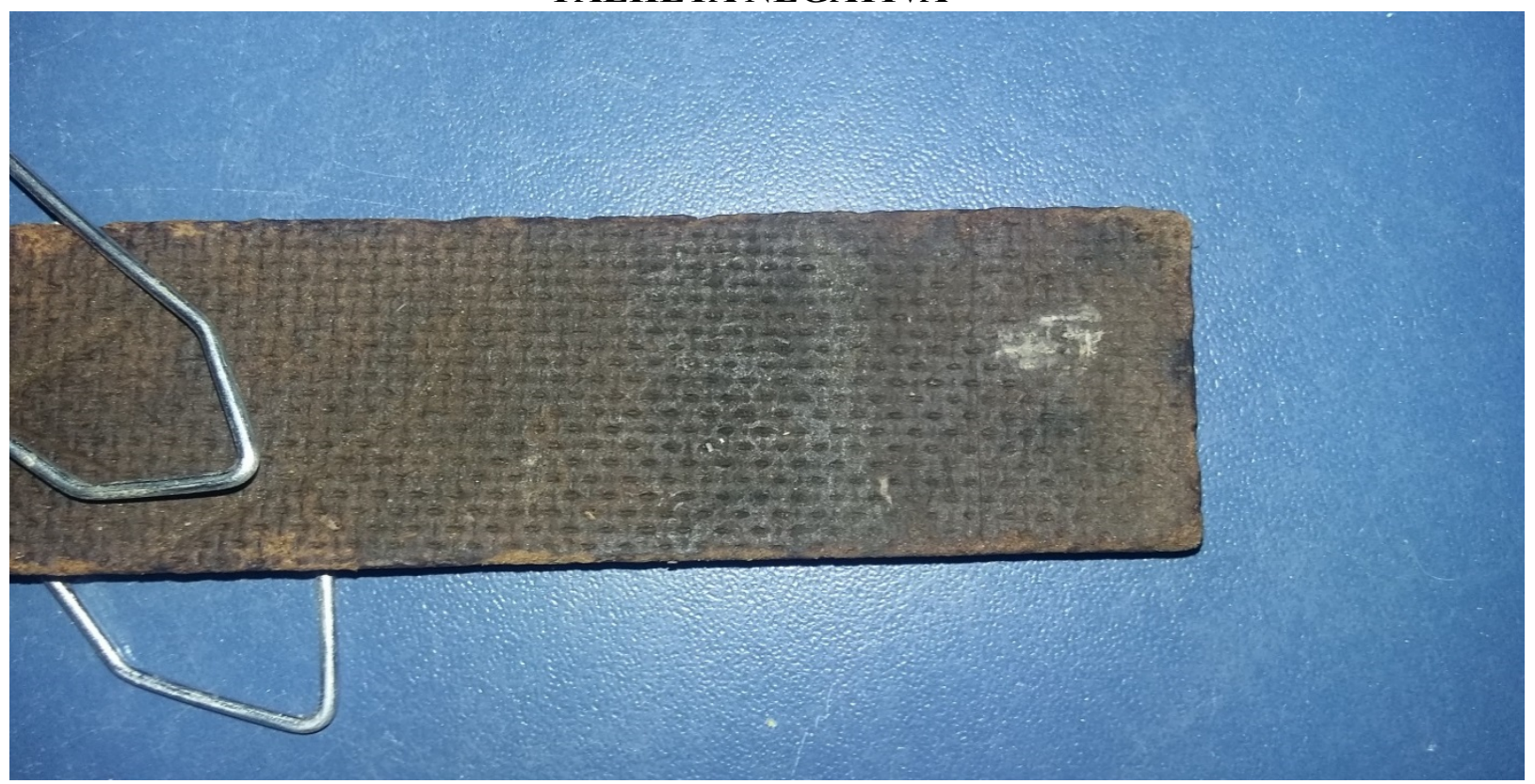


PALHETA POSITIVA

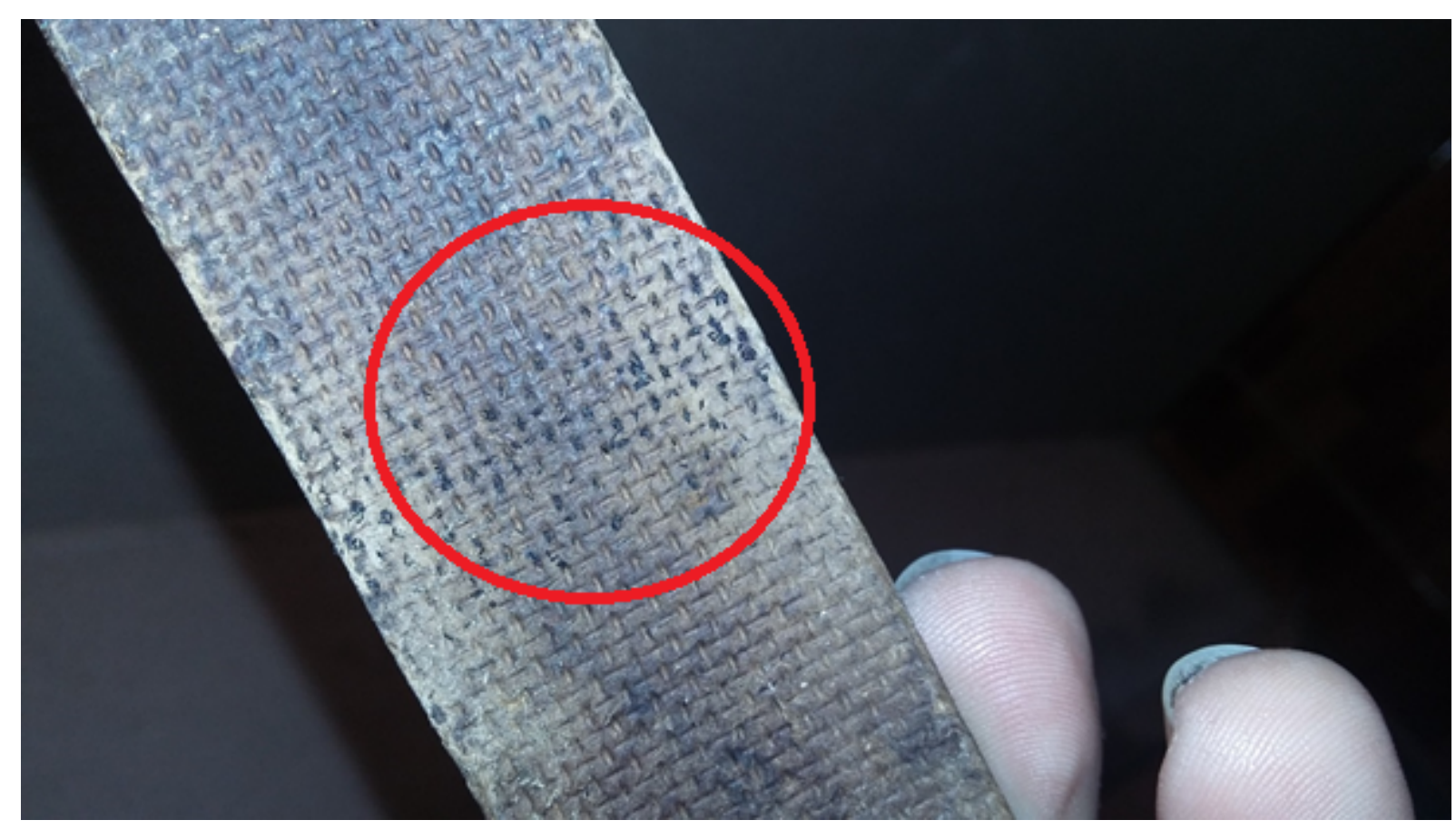

PARTICIPAÇÃO V MOSTRA UFCA JUAZEIRO DO NORTE

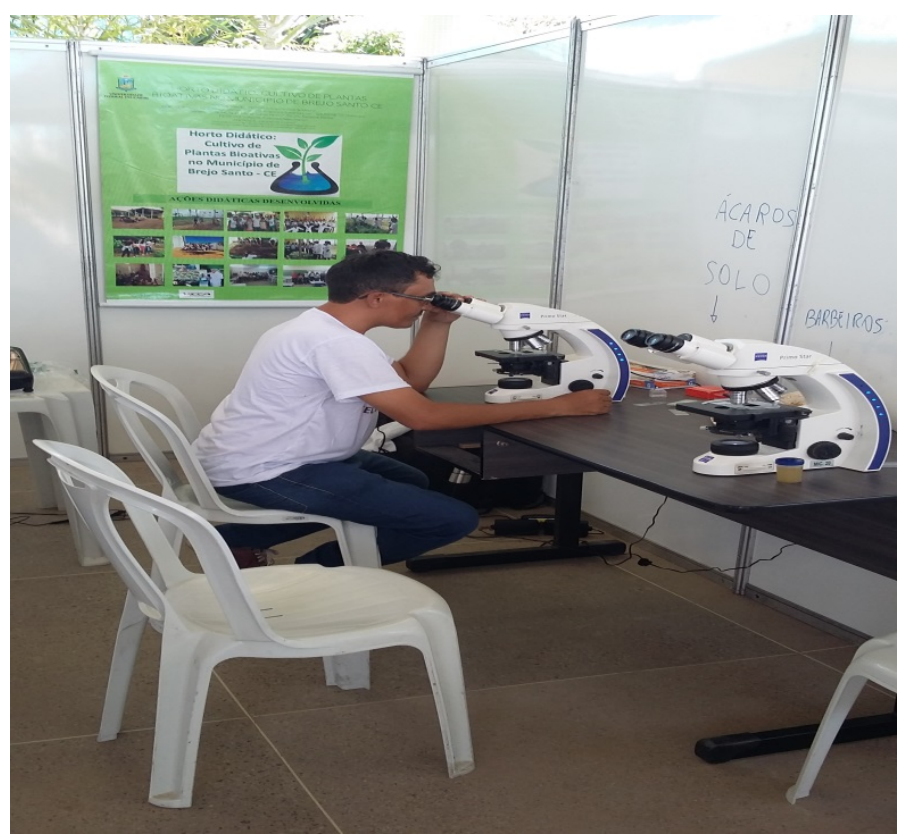




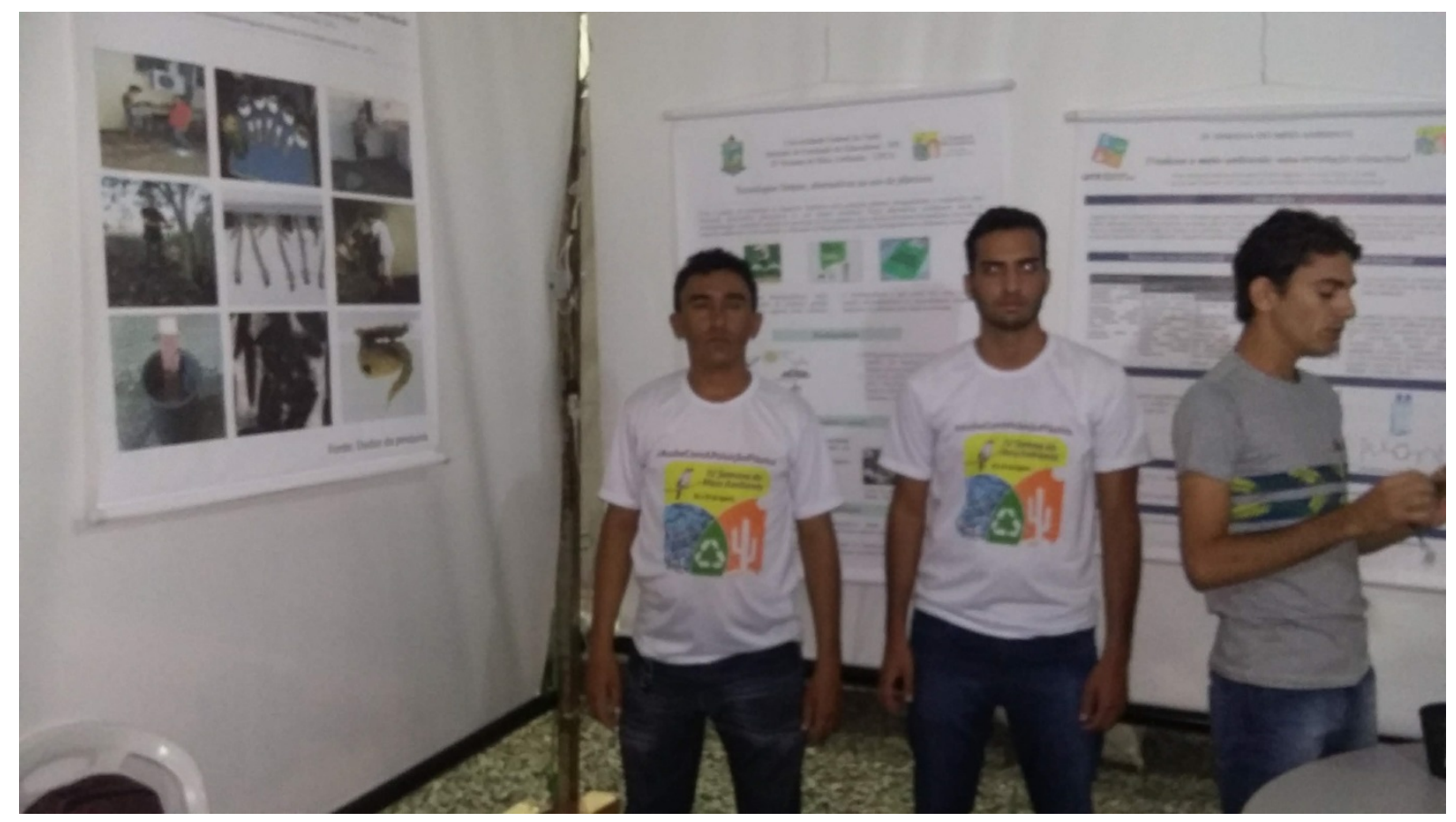


